University of Wollongong

Research Online

Faculty of Engineering - Papers (Archive)

Faculty of Engineering and Information

Sciences

$1-1-2006$

\title{
Synthesis and characterization of one-dimensional CdSe nanostructures
}

G. X. Wang

University of Wollongong, gwang@uow.edu.au

M. S. Park

University of Wollongong

Hua-Kun Liu

University of Wollongong, hua@uow.edu.au

D. Wexler

University of Wollongong, davidw@uow.edu.au

Jun Chen

University of Wollongong, junc@uow.edu.au

Follow this and additional works at: https://ro.uow.edu.au/engpapers

Part of the Engineering Commons

https://ro.uow.edu.au/engpapers/108

\section{Recommended Citation}

Wang, G. X.; Park, M. S.; Liu, Hua-Kun; Wexler, D.; and Chen, Jun: Synthesis and characterization of onedimensional CdSe nanostructures 2006.

https://ro.uow.edu.au/engpapers/108

Research Online is the open access institutional repository for the University of Wollongong. For further information contact the UOW Library: research-pubs@uow.edu.au 


\title{
Synthesis and characterization of one-dimensional CdSe nanostructures
}

\author{
G. X. Wang, ${ }^{\text {a) }}$ M. S. Park, and H. K. Liu \\ Institute for Superconducting and Electronic Materials, University of Wollongong, New South Wales 2522, \\ Australia and ARC Centre of Excellence for Electromaterials Science, University of Wollongong, \\ New South Wales 2522, Australia \\ D. Wexler \\ School of Mechanical, Materials and Mechatronic Engineering, University of Wollongong, \\ New South Wales 2522, Australia \\ J. Chen \\ ARC Centre of Excellence for Electromaterials Science, Intelligent Polymer Research Institute, \\ University of Wollongong, New South Wales 2522, Australia
}

(Received 12 January 2006; accepted 22 March 2006; published online 10 May 2006)

\begin{abstract}
One-dimensional (1D) CdSe nanostructures, including nanowires, nanotubes, nanorods, nanobelts, and even nanostructures resembling saws and tree branches, have been synthesized by sublimation of CdSe powders under various experimental conditions. These 1D CdSe nanostructures were characterized by scanning electron microscopy, high resolution transmission electron microscopy observations, and Raman spectroscopy. Energy dispersive x-ray spectroscopy analysis confirmed the chemical stoichiometry of the CdSe nanostructures. It was found that the geometrical morphologies of the CdSe 1D nanostructures were significantly influenced by the synthetic parameters. Raman spectra of CdSe nanowires show an upward shift of the 2LO phonon peak. (C) 2006 American Institute of Physics. [DOI: 10.1063/1.2202725]
\end{abstract}

The synthesis, characterization, and assembly of semiconductor nanowires have been extensively investigated worldwide, because they are building blocks for fabricating functional nanoscale systems with a wide range of technological applications, including nanoelectronics, photonics, nanocomputing, data processing, and biological and medical sensing. ${ }^{1-3} \mathrm{CdSe}$ is an important II-VI semiconductor. CdSe nanocrystals have demonstrated robust memory effects with potential for quantum memory applications. Light has been found to restore or even increase the conduction of a $\mathrm{CdSe}$ nanocrystal array. ${ }^{4} \mathrm{CdSe}$ nanocrystals have also been used to fabricate inorganic thin-film transistors with high field mobilities ${ }^{5}$ and to fabricate hybrid polymer solar cells with a power conversion efficiency of $6.9 \%$ for green light. ${ }^{6}$ Quantum confinement of CdSe nanocrystals has been extensively investigated because the band gap of CdSe quantum dots (QDs) increases with decreasing size of the QD. ${ }^{7-10}$ Previously, there were reports of the synthesis of CdSe quantum nanowires by solution-liquid-solid growth ${ }^{11,12}$ and by electrodeposition. ${ }^{13}$ One-dimensional CdSe nanostructures have been found in the form of nanowires, nanoribbons, and even "nanosaws.", ${ }^{214}$ Here, we report the synthesis of a variety of CdSe one-dimensional (1D) nanostructures, including CdSe nanowires, nanorods, nanoribbons, and nanotubes, produced via a vapor-liquid-solid growth approach. The optical properties of CdSe nanowires were examined by Raman spectroscopy.

CdSe powders ( $1 \mu \mathrm{m}, 99.99 \%$, Aldrich) were placed in an alumina boat inside a quartz tube furnace. Silicon substrates were sputtered with a layer of $\mathrm{Au}$ particles (about $40 \AA$ thick). The substrate was placed at different distances from the boat. The temperature of the CdSe source was set at

\footnotetext{
${ }^{a)}$ Author to whom correspondence should be addressed; electronic mail: gwang@uow.edu.au
}

$850-950{ }^{\circ} \mathrm{C}$, and the substrate at approximately $800-950{ }^{\circ} \mathrm{C}$. CdSe powders were sublimated under Ar flow at a rate of 50-100 SCCM (standard cubic centimeter per minute at STP) for $30 \mathrm{~min}$. After deposition, CdSe nanolayers were peeled off from the substrate via ultrasonication. The morphologies and structures of the CdSe nanostructures were examined by scanning electron microscopy (SEM, JEOL 6460) and transmission electron microscopy (TEM, JEOL 2011). Raman spectroscopy was employed to characterize the optical properties of the CdSe 1D nanostructures using a Jobin Yvon HR800 confocal Raman system with $632.8 \mathrm{~nm}$ diode laser excitation on a 300 lines $/ \mathrm{mm}$ grating at room temperature.

The morphologies of the CdSe 1D nanostructures were characterized by SEM observation. Figure 1 shows SEM images of various CdSe 1D nanostructures. We found that the CdSe nanostructures were significantly influenced by the synthetic parameters such as the heating temperature, the flow rate of the carrying gas, the position of the substrate, and the synthesis time. We have prepared CdSe nanostructures under different synthetic conditions. Figure 1(a) shows CdSe nanowires obtained at $850^{\circ} \mathrm{C}$ and 50 SCCM Ar flow. The as-prepared CdSe nanowires have diameters in the range of 40-100 $\mathrm{nm}$ and lengths ranging from a few micrometers to tens of micrometers. These CdSe nanowires are curly in nature. The straight $\mathrm{CdSe}$ nanowires and nanorods were produced under the conditions of $900{ }^{\circ} \mathrm{C}$ with a flow rate of 50 SCCM on a substrate covering the alumina boat [Fig. 1(b)]. At the same temperature of $900{ }^{\circ} \mathrm{C}$, when the Ar flow rate was increased to $200 \mathrm{SCCM}$, we collected CdSe nanobelts/nanoribbons [Fig. 1(c)] on a substrate placed at a distance of $50 \mathrm{~mm}$ from the alumina boat. As the temperature was further increased to $950{ }^{\circ} \mathrm{C}$ with an $\mathrm{Ar}$ flow rate of $30 \mathrm{SCCM}, \mathrm{CdSe}$ nanosaw structures were obtained on a substrate covering the alumina boat [Fig. 1(d)]. However, at the 


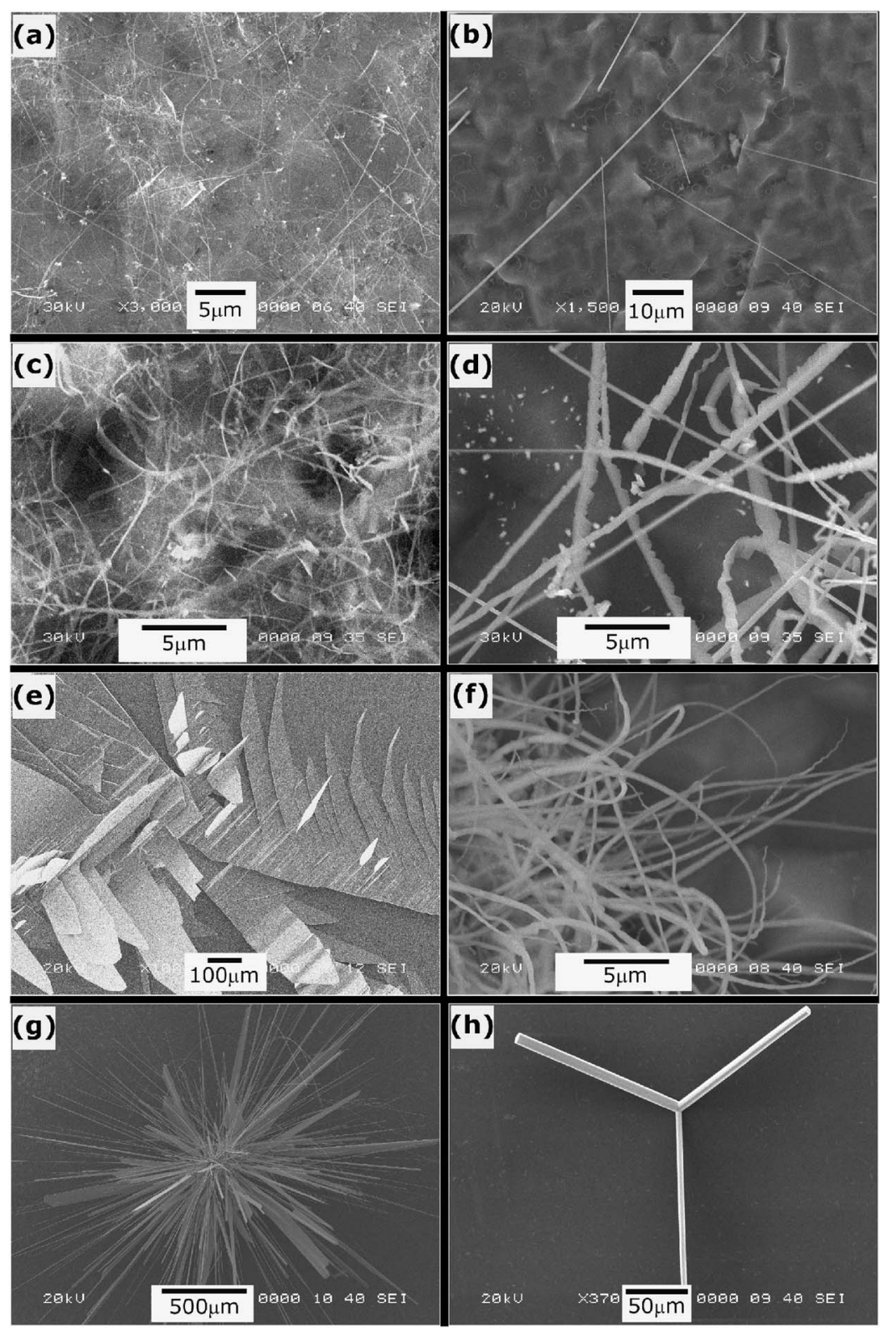

FIG. 1. SEM images of different morphologies of CdSe 1D nanostructures synthesized under various conditions: (a) $880{ }^{\circ} \mathrm{C}, 50 \mathrm{SCCM}$, and substrate location: $50 \mathrm{~mm}$ from the $\mathrm{Al}_{2} \mathrm{O}_{3}$ boat; (b) $900{ }^{\circ} \mathrm{C}, 50 \mathrm{SCCM}$, and substrate location: covering the $\mathrm{Al}_{2} \mathrm{O}_{3}$ boat; (c) $900{ }^{\circ} \mathrm{C}, 200 \mathrm{SCCM}$, and substrate location: $50 \mathrm{~mm}$ from the $\mathrm{Al}_{2} \mathrm{O}_{3}$ boat; (d) $950{ }^{\circ} \mathrm{C}, 30 \mathrm{SCCM}$, and substrate location: covering the $\mathrm{Al}_{2} \mathrm{O}_{3}$ boat; (e) $950{ }^{\circ} \mathrm{C}$, $80 \mathrm{SCCM}$, and substrate location: covering the $\mathrm{Al}_{2} \mathrm{O}_{3}$ boat; (f) $950{ }^{\circ} \mathrm{C}, 30 \mathrm{SCCM}$, and substrate location: $60 \mathrm{~mm}$ from the $\mathrm{Al}_{2} \mathrm{O}_{3}$ boat; (g) $950{ }^{\circ} \mathrm{C}, 30 \mathrm{SCCM}$, and substrate location: covering the $\mathrm{Al}_{2} \mathrm{O}_{3}$ boat; and (h) $950{ }^{\circ} \mathrm{C}, 15 \mathrm{SCCM}$, and substrate location: covering the $\mathrm{Al}_{2} \mathrm{O}_{3}$ boat.

same temperature and substrate position, CdSe nanostructures resembling palm-tree leaves [Fig. 1(e)] were produced under the increased flow rate of 80 SCCM. CdSe "nanoropes" [Fig. 1(f)] with diameters in the range of a few hundred nanometers were synthesized at $950{ }^{\circ} \mathrm{C}$, with $30 \mathrm{SCCM}$ Ar flow on a substrate located at $60 \mathrm{~mm}$ from the alumina boat. Interestingly, CdSe flowerlike structures [Fig. 1(g)] were obtained on a substrate covering the alumina boat under the same conditions as for Fig. 1(f). When we reduced the Ar flow rate to $15 \mathrm{SCCM}$, we observed a CdSe "Y" shaped microbranch structure [Fig. 1(h)]. The above SEM observations clearly demonstrate that the CdSe 1D nanostructures were dynamically influenced by the synthetic parameters.

The CdSe deposits were peeled off from the Si substrate via ultrasonic vibration for TEM analysis. Figure 2 shows TEM images of the CdSe nanowires, nanotubes, and nanorods. Figure 2(a) exhibits the morphology of a straight $\mathrm{CdSe}$ nanowire with a diameter of $\sim 70 \mathrm{~nm}$. High-resolution transmission electron microscopy (HRTEM) observations provided insight into the structure of CdSe nanowires. Figure 2(b) shows a HRTEM image of this CdSe nanowire, demonstrating the lattice details of the CdSe nanostructure. It re-

Downloaded 03 Aug 2006 to 130.130 .37 .6. Redistribution subject veals fringe contrast consistent with (0002) planes and the growth of the CdSe nanowire along the $\langle 0001\rangle$ direction. The fringe of the $\mathrm{CdSe}$ nanowire has a regular comb texture. There also was no evidence of an oxidation layer at the edge of the CdSe nanowires, indicating that the CdSe nanowires are stable against oxidation. We measured the $d$ spacing for the CdSe (0002) lattice plane to be $3.5 \AA$. This HRTEM lattice image demonstrates that the CdSe nanowire is single crystalline in nature and free from dislocations and stacking faults. Figure 2(c) shows a much larger, straight nanorod with a diameter of $\sim 250 \mathrm{~nm}$. In this case it was possible to orient the rod in order to obtain a zone axis selected area electron diffraction (SAED) pattern, verifying the singlecrystalline hexagonal wurtzite structure and a growth direction of the CdSe nanowire along [0001]. Figure 2(d) shows a short $\mathrm{CdSe}$ nanotube grown from $\mathrm{Au}$ nanoclusters. Figure 2(e) further shows another long and straight CdSe nanotube. The detailed texture of the CdSe nanotube corresponding to Fig. 2(d) is shown in Fig. 2(f), clearly illustrating the lattice in the edge region and the hollow core in the center. This CdSe nanotube has an outer diameter of $\sim 30 \mathrm{~nm}$ and an inner diameter of $\sim 10 \mathrm{~nm}$. Energy dispersive spectroscopy AIP license or copyright, see http://apl.aip.org/apl/copyright.jsp 


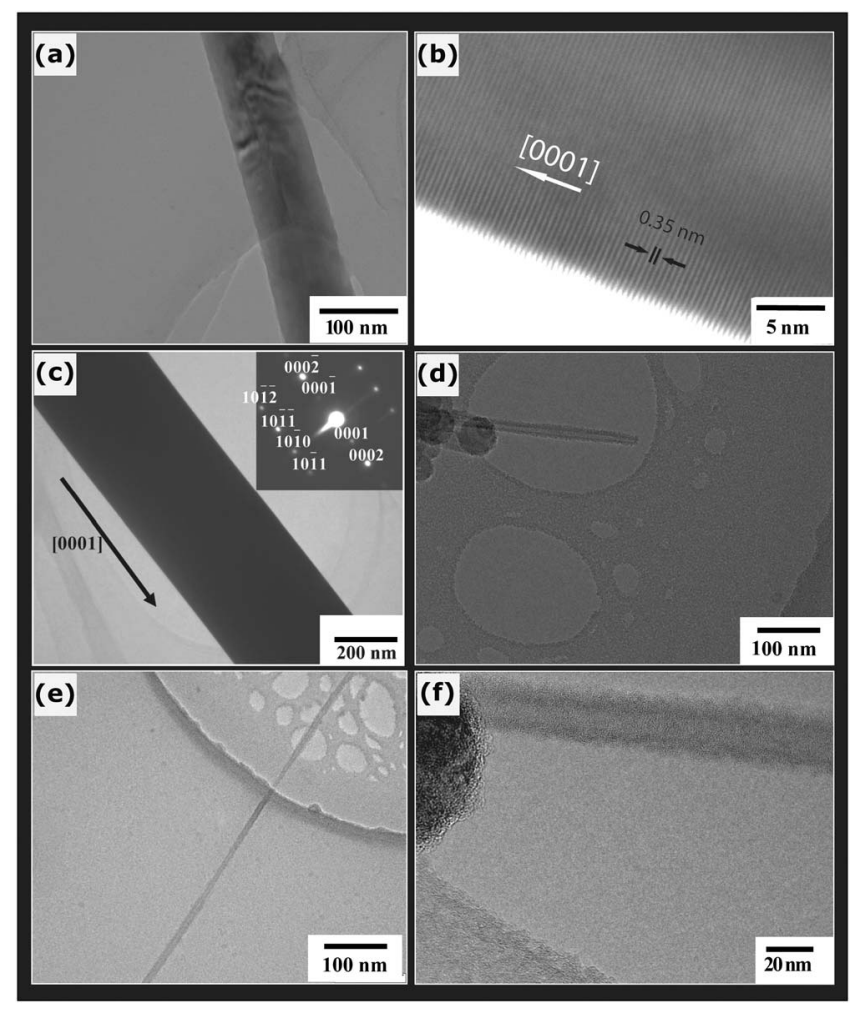

FIG. 2. TEM images of CdSE 1D nanostructures: (a) A straight CdSe nanowire; (b) HRTEM image of CdSe nanowire; (c) a coarse straight CdSe nanorod and associated selected area electron diffraction, zone axis is [12 10$]$ and growth direction is $\langle 0001\rangle$; (d) a short CdSe nanotube; (e) a long and straight CdSe nanotube; and (f) high magnification image of CdSe nanotube.

(EDS) analysis was performed on many individual CdSe nanowires, nanorods, and nanotubes, indicating a composition of $\mathrm{Cd}$ and Se with a stoichiometry ratio of 1:1.

The room temperature Raman spectra of CdSe nanowires and CdSe microcrystalline powders are displayed in Fig. 3. It shows the phonon frequencies of the longitudinal optical (LO) and 2LO modes of CdSe at 206.2 and $418.8 \mathrm{~cm}^{-1}$, respectively. The corresponding Raman shift of 2LO phonons of CdSe nanowires is located at $423.9 \mathrm{~cm}^{-1}$, showing an upward shift of the $2 \mathrm{LO}$ mode of about $5 \mathrm{~cm}^{-1}$. The Raman peak of the LO mode for CdSe nanowires is very weak and almost invisible. The nanowires have much higher surface areas and more surface defects than crystalline CdSe powders. This could have induced the weakening of the LO phonons and the upward shift of the 2LO modes. Because the as-prepared CdSe nanowires have diameters in the range of 40-100 nm, quantum confinement of the phonon motions due to the size effect is negligible, and therefore is unlikely to significantly contribute to this upward shift.

In summary, a variety of one-dimensional (1D) cadmium selenide nanostructures were synthesized by sublimation of CdSe powders. We have identified numerous factors influ-

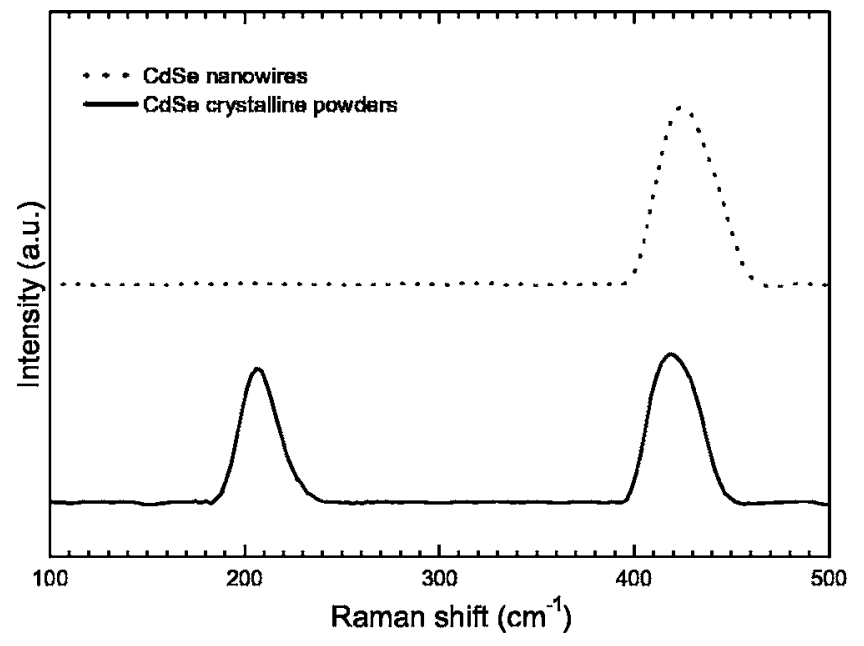

FIG. 3. Raman spectra of crystalline CdSe powders and CdSe nanowires.

encing the growth, morphologies, and dimensionality of CdSe 1D nanostructures, illustrating that the geometrical characteristics of $\mathrm{CdSe}$ nanostructures can be controlled by the synthetic parameters. Raman spectra measurements show an upward shift of the $2 \mathrm{LO}$ phonon peak of CdSe nanowires. One-dimensional CdSe nanostructures could provide functional building blocks for nanoscale electronic and optoelectronic devices. However, it is necessary to further map the controllable synthesis of CdSe 1D nanostructures.

This work was supported by the Australian Research Council through the ARC Discovery Project "Synthesis of nanowires and their application as nanosensors for chemical and biological detection" (DP0559891) and the ARC Centre of Excellence for Electromaterials Science.

${ }^{1}$ Y. Cui, Q. Q. Wei, H. K. Park, and C. M. Lieber, Science 293, 1289 (2001).

${ }^{2}$ C. Ma and Z. L. Wang, Adv. Mater. (Weinheim, Ger.) 17, 2635 (2005).

${ }^{3}$ D. M. Whang, J. Song, Y. Mu, and C. M. Lieber, Nano Lett. 3, 1255 (2003).

${ }^{4}$ M. D. Fischbein and M. Drndic, Appl. Phys. Lett. 86, 193106 (2005).

${ }^{5}$ B. A. Ridley, B. Nivi, and J. M. Jacobson, Science 286, 746 (1999).

${ }^{6}$ W. U. Huynh, J. J. Dittmer, and A. P. Alivisatos, Science 295, 2452 (2002).

${ }^{7}$ K. E. Andersen, C. Y. Fong, and W. E. Pickett, J. Non-Cryst. Solids 299-302, 1105 (2002).

${ }^{8}$ R. W. Meulenberg and G. F. Strouse, Phys. Rev. B 66, 035317 (2002).

${ }^{9}$ H. Yu, J. B. Li, R. A. Loomis, P. C. Gibbons, L. W. Wang, and W. E. Buhro, J. Am. Chem. Soc. 125, 16168 (2003).

${ }^{10}$ X. B. Chen, A. C. S. Samia, Y. B. Lou, and C. Burda, J. Am. Chem. Soc. 127, 4372 (2005).

${ }^{11}$ H. Yu, J. Li, R. A. Loomis, L. W. Wang, and W. E. Buhro, Nat. Mater. 2, 517 (2003)

${ }^{12}$ H. Yu and W. E. Buhro, Adv. Mater. (Weinheim, Ger.) 15, 416 (2003).

${ }^{13}$ X. S. Peng, J. Zhang, X. F. Wang, Y. W. Wang, L. X. Zhao, G. W. Meng, and L. D. Zhang, Chem. Phys. Lett. 343, 470 (2001).

${ }^{14}$ C. Ma, Y. Ding, D. F. Moore, X. Wang, and Z. L. Wang, J. Am. Chem. Soc. 126, 708 (2004). 